\title{
Evolution of a Chinese-Canadian Educational Partnership
}

\section{Dr. Ronald J Hugo, University of Calgary}

Ronald J. Hugo is Professor of Mechanical and Manufacturing Engineering and Associate Dean (Teaching \& Learning) at the University of Calgary. He is also the holder of the Engineering Education Innovation Chair in the Schulich School of Engineering. His research interests are in the areas of experimental fluid dynamics, energy systems, and engineering education.

\section{Dr. Bob Brennan, University of Calgary \\ Dr. Jian Zhang \\ Dr. Xiaodong Niu, Shantou University}

Niu Xiaodong is currently a full professor and Head of Department of Mechatronics Engineering in Shantou University in China. He obtained his Ph.D. in department of Mecahnical Engineering in National University of Singapore in 2004. His earlier academic career includes:2008 2011, Associate Professor of Doshisha University and, 2006 2008, Visiting Researcher of Toyota Central R\&D Labs., Inc. in Japan, His majors are computaional and exeperimental fluid mechanics, particularly on lattice Boltizmann method and magnetic fluids. 


\section{Evolution of a Chinese-Canadian Educational Partnership}

\section{Introduction:}

Over the last three decades, the internet has accelerated interconnectedness. From this interconnectedness, the appearance of the "micro-multinational" or small to medium-sized company that operates internationally has become a major contender. Given the highly international level of economic activity now seen ${ }^{1}$, engineering graduates will likely be called upon to navigate effectively in the global economy.

In response to economic needs, post-secondary institutions have begun to address ways that global competency can be integrated into engineering programs. Five educational methods that can be used to help develop global competency are listed below:

1. International enrolment refers to the traditional student exchange where students enrol and study for either one semester or an academic year at an institution located in another country.

2. International project refers to a senior-year capstone design project with the involvement of another (host) country, often including sponsors and co-workers from the host country.

3. International work placement involves work at a foreign firm for a duration that ranges anywhere from 4 months to an entire year.

4. International field trip is usually a short-duration visit (one to two weeks) to one or more foreign countries, often including visits to other universities, research laboratories, and industrial establishments (factories, plants, etc.).

5. Integrated class experience refers to an at-home effort that includes activities that range from education in the language, customs, history, and government of the country in question. (Downey et al. ${ }^{2}$ )

This paper describes the evolution of an international collaboration between the University of Calgary (UCalgary) in Alberta, Canada and Shantou University (STU) in Guangdong Province, China. The collaboration is best described as a hybrid between International enrolment, International project, and International field trip. The paper begins with a history of the program. Next is a description of how Transformative Reflection was used to help the program evolve. This section is followed by how the program and workspaces have evolved from year to year. The paper concludes with planned and potential changes for future years of program delivery.

\section{Program Formation:}

In 2008, an agreement was established between UCalgary and STU. This agreement resulted in the Global Leadership and Innovation group study program which involved students from UCalgary traveling to Shantou University. Together, the students from both universities took two non-engineering courses offered via a traditional lecture-based approach. 
In February 2009, a group of 33 UCalgary engineering students traveled to China for an elevenday non-credit group travel program. The program included 3 days in Beijing and 7 days at Shantou University. In an effort to bolster inter-cultural understanding, a week-long projectbased learning experience involving the 33 UCalgary students and an equal number of STU students was planned. This collaboration was enhanced by the participation of both universities in CDIO (Conceive-Design-Implement-Operate), an international engineering education reform initiative. The project-based learning collaboration proved to be a success in intercultural exchange $^{3}$, inspiring the program architects to pursue a formal, for-credit collaboration.

In February 2010, one of the authors of this paper became the Chair in Engineering Education Innovation at UCalgary. Funding for this endowed chair program was provided through the Li Ka Shing (Canada) Foundation. The Li Ka Shing Foundation also supports Shantou University along with the Ministry of Education and the Guangdong Provincial Government. The common support through the Li Ka Shing Foundation helped to establish the UCalgary-STU collaboration described in this paper. Partial funding from the endowed chair program at UCalgary has assisted in the development of aspects of the program as described in this paper.

Based on the success of the 2009 pilot program and the common link provided through the Li Ka Shing Foundation, an engineering-specific group study program that involved project-based learning was developed. This led to the formation of an Inquiry-Based Learning course (Renewable Energy Practicum) which was designed to provide students with hands-on learning in relation to renewable energy. It also led to the formation of a Project-Based Learning course (Innovation and Entrepreneurship in Renewable Energy) that combined the engineering design process and entrepreneurship. The original inspiration for this second course came from an article published by Sullivan et al. ${ }^{4}$.

UCalgary and STU have now partnered five times through the UCalgary Group Study travel program. Each May, 20 UCalgary students travel to STU where they take two courses alongside 20 STU students. The program has been delivered in English and primarily by the UCalgary Chair in Engineering Education Innovation.

\section{Reflective Teaching:}

In the five years that the program has been operational, significant evolution has taken place through the process of Reflective Teaching and Transformative Reflection ${ }^{5}$. As described by Biggs and Tang ${ }^{5}$, this process consists of multi-stages: reflect-plan-apply-evaluate (did it work?). The course instructor records daily observations, (see journal in Figure 1). Journal entries include program observations, reminders for future program improvement, or notes outlining activities for that specific day. At the end of the program, the journal is scanned and stored on an iPad. This allows the course instructor easy access to journals from previous years. The journal is reviewed at the conclusion of the program and is used to drive change for the following year. 


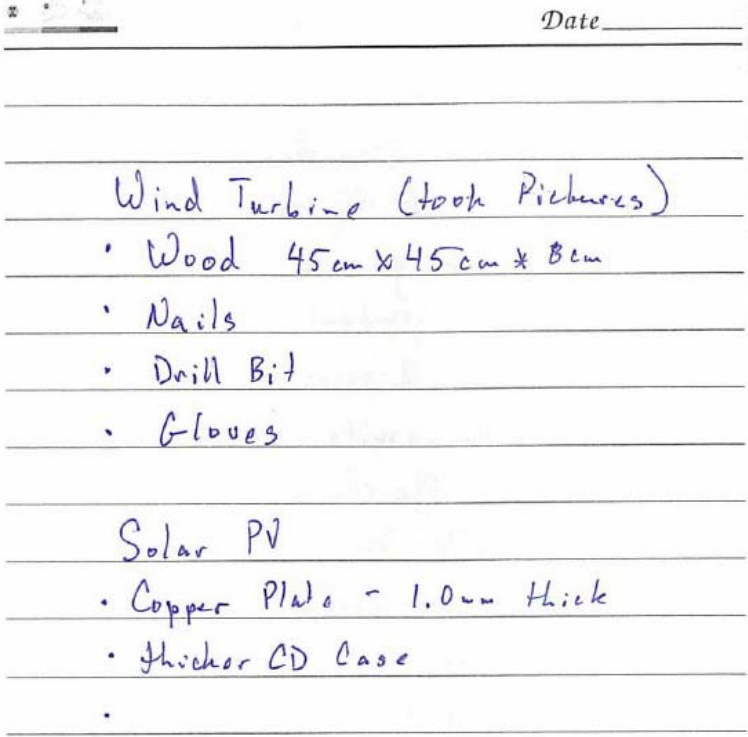

Figure 1: Example of Daily Journal Entry by Course Instructor

Another source of feedback comes from end-of-program student interviews. During this session, students are randomly placed within groups and asked to come up with three strengths about the program and three suggestions for improvement. Student teams need to come to a consensus about the strengths and suggestions. The students then rate all of the strengths and suggestions for improvement on a scale of 1 (strongly disagree) to 5 (strongly agree). This data is tabulated so as to determine the strengths and suggestions with strongest agreement. This information is also used to drive program change for the subsequent year.

A final source of feedback comes from student evaluations that are also administered at the conclusion of the program. The instrument used for these evaluations is a standard UCalgary instrument referred to as the USRI (Universal Student Rating of Instruction). Results for the USRI for each year of the program, categorized as either UCalgary or STU feedback, are shown in Figure 2 and Figure 3. 

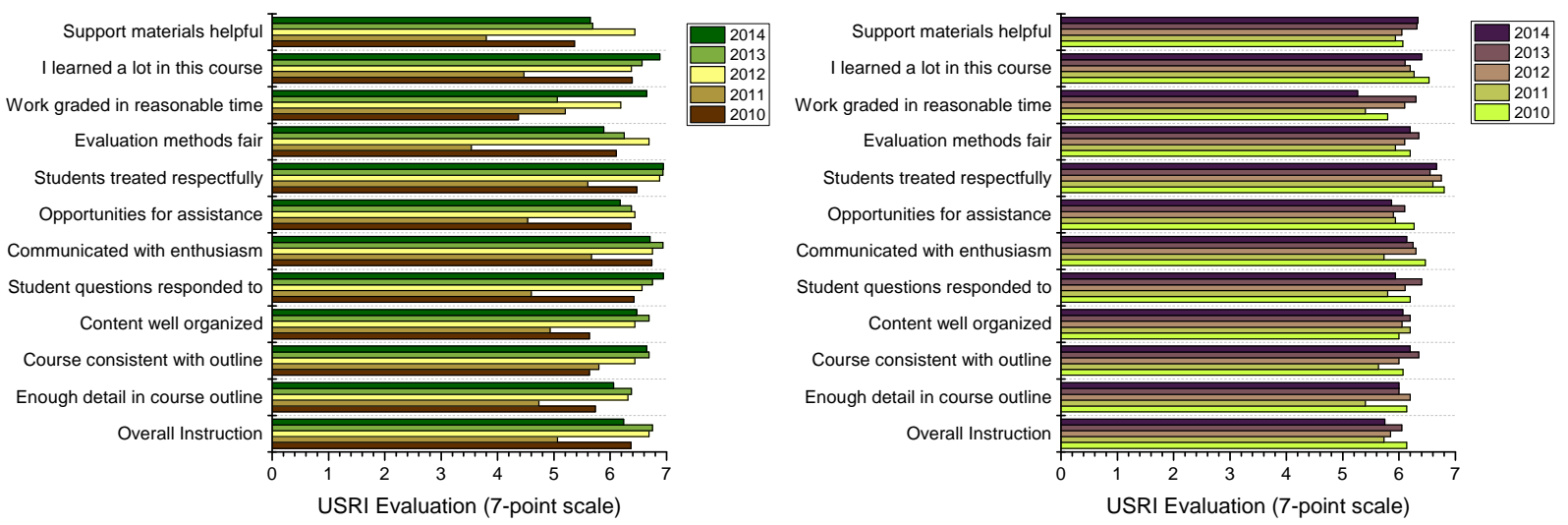

Figure 2: Innovation and Entrepreneurship in Renewable Energy (UCalgary - left; STU - right)
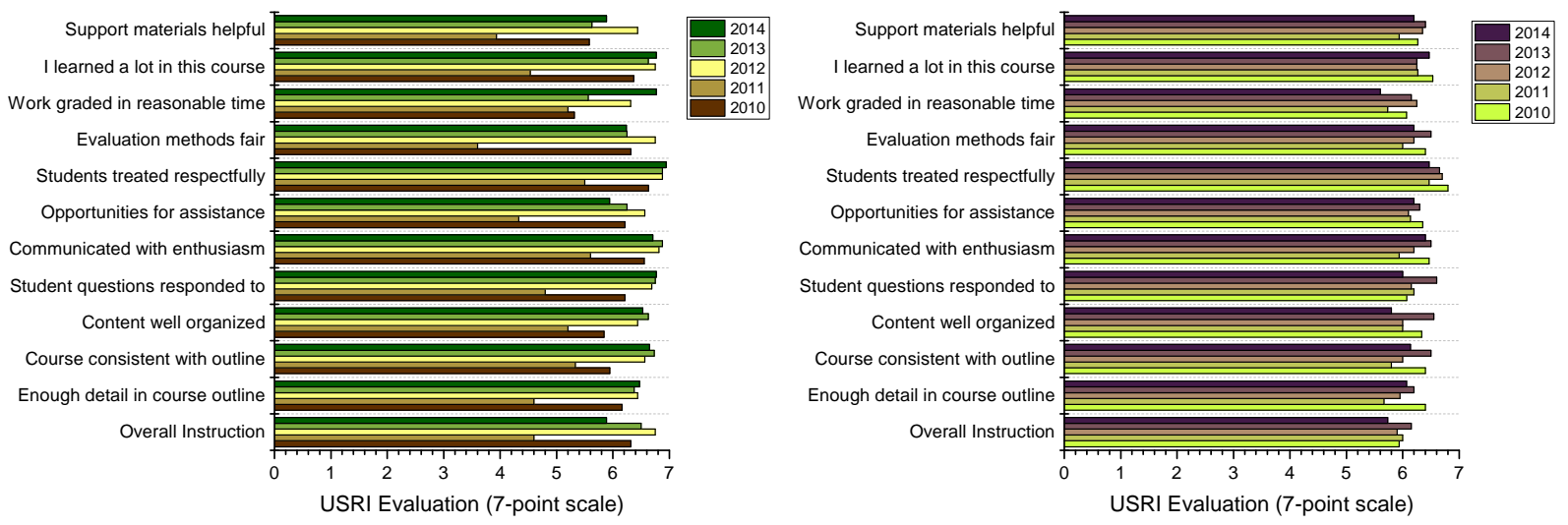

Figure 3: Renewable Energy Practicum (UCalgary - left; STU - right)

\section{Program Evolution:}

The five-year evolution of the group study program is shown graphically in Figure 4. The Innovation and Entrepreneurship in Renewable Energy course, traditionally offered in the morning (8:30-10:00 a.m.), is shown on the left. The Renewable Energy Practicum course, typically offered in the afternoon (2:00-6:00 p.m.), is on the right. Each of the columns in the figure denotes the course structure for a particular year. Common color coding exists between the two courses. This includes Arrival in Shantou; Days Off for the students; Field Trips to locations outside of Shantou; and the final program Expo that concludes the two courses. Coding specific to the Innovation and Entrepreneurship in Renewable Energy course includes Lectures; an Interview to obtain feedback from the students; and Project time for the student groups to engage in independent work. Coding specific to the Renewable Energy Practicum course includes four Inquiry-Based Learning projects: Solar Cell (solar photovoltaic cell);

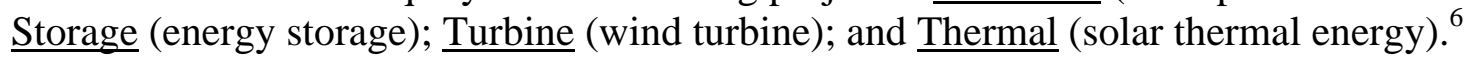

By examining the top of each column, it is to be noted that each year the program start day varies. Calgary departure can only take place after the Winter semester (January-April) final 
exam period at the UCalgary has concluded. It should also be noted that occasionally a lecture takes place in the morning, and then a field trip initiates in the afternoon.

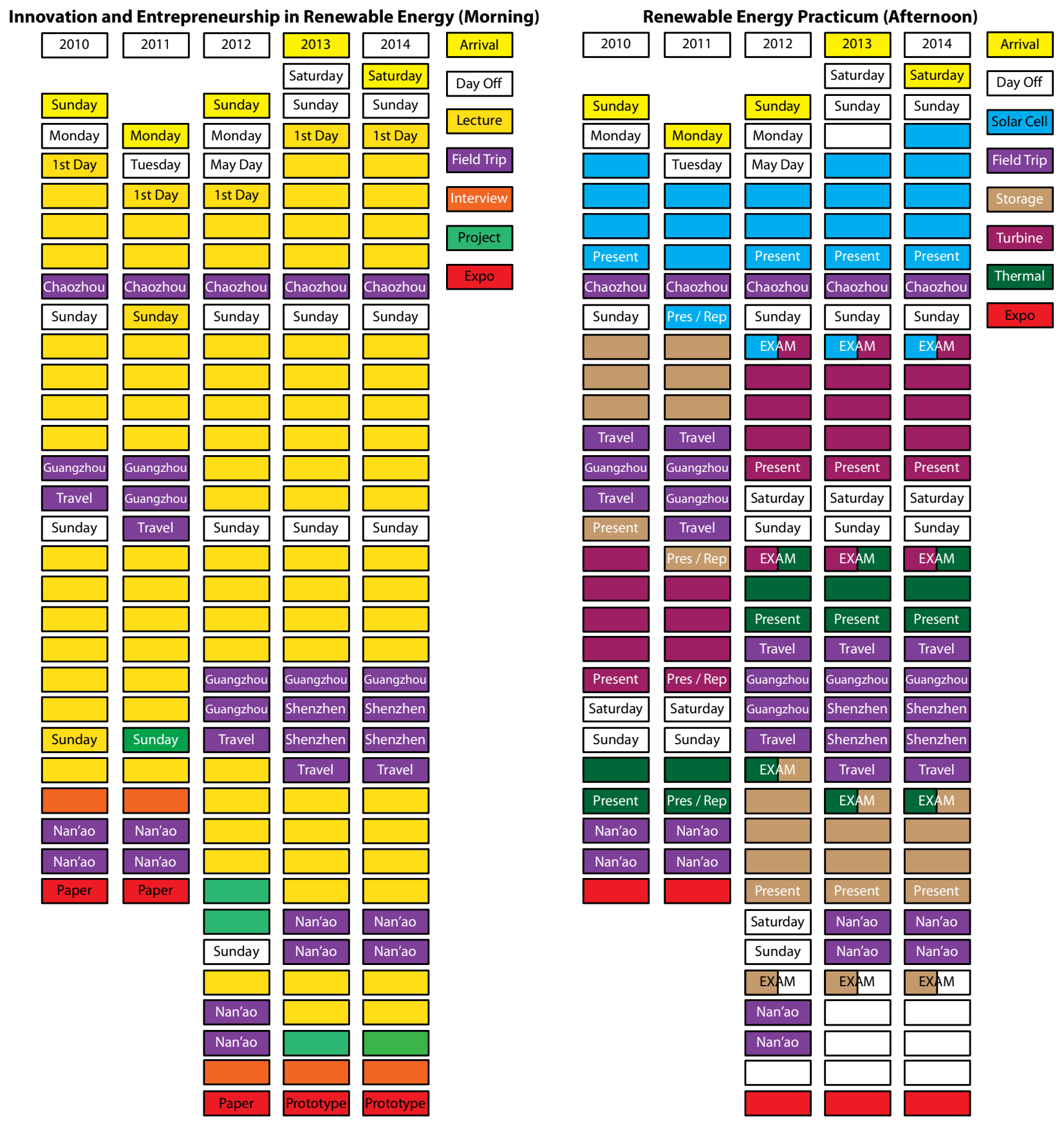

Figure 4: Five-Year Evolution of the Structure of the Two Courses

Year 1 - 2010: The program was offered for the first time in May 2010. The program duration was 28 days (including both the arrival and departure days). The Project-Based Learning design in the Innovation and Entrepreneurship in Renewable Energy course involved a paper-based design. Although it was desired to have students build and test their project ideas as in the course offered by Sullivan et al. ${ }^{4}$, it was deemed impossible given the short time that remained in 
the program after student teams had finished their designs and before the end of the program (one or two days). Materials and supplies for the Renewable Energy Practicum course were either purchased locally in China or mail-ordered from the US to Canada, repackaged and then shipped from Canada to China. The mail-ordered components were specialized: rare-earth magnets (wind turbine experiment) and DC-DC voltage converters (energy storage experiment).

Year 2 -2011: The second year of the program was one day shorter at 27 days (including both arrival and departure days). Three main changes were made during the second year. The first was an additional day for the field trip to Guangzhou. This field trip involved a 6-hour bus ride from Shantou to Guangzhou on Thursday afternoon; a factory visit on Friday morning; a visit to a university in Guangzhou on Friday afternoon; and then a free day for students to explore the city on Saturday. Return travel took place on Sunday morning, again via a 6-hour bus ride. The addition of the free day in Guangzhou was in response to student feedback from 2010 requesting more independent exploration time, especially while visiting Guangzhou.

The second main change consisted of the addition of a written group report for each of the four experiments in the Renewable Energy Practicum course, as indicated by Pres / Rep (Presentation and Report) in the 2011 column to the right in Figure 4. A third main change included the requirement that students write and submit a Business Plan document as part of the Innovation and Entrepreneurship in Renewable Energy course. As indicated in the UCalgary student evaluations for 2011 in both Figure 2 and Figure 3, the increased workload in both courses resulted in what could best be described as a "meltdown" in the student-instructor relationship. As noted on the left in Figure 4, the program design in 2011 involved little to no down-time for students and the instructor. The addition of written reports led to further student dissatisfaction, as reflected by the USRI results. The situation was exacerbated by extremely inconsistent internet access on college campuses in China during the spring of 2011. This highlights an important point of any group study program. It can be challenging to find the proper balance between too much work and not enough work. Although it is desired for students to experience the culture in their new study environment, the program needs to be more than the International Field Trip as described by Downey et al. ${ }^{2}$ Finding this optimal balance therefore requires careful monitoring of student behaviour.

Year 3 - 2012: Based on the student meltdown that took place during Year 2 and on feedback obtained from the students during the end-of-program interviews, it was decided to extend the program to 35 days for Year 3. This enabled another set changes to the program. The first was the welcomed addition of several days off to the program. The second was to move the field trip to Guangzhou from the second to the third week. Given that the purpose of the field trip was to visit a factory that makes small wind turbines for street lighting applications, it was decided to move the wind turbine experiment one week earlier so that it would take place prior to the factory visit. The result of this was extremely positive as student interest in the factory was much higher after they had built and tested their own wind turbine. The CEO of the company, who was present during the 2013 visit, commented on how astute the student questions were.

Another change to the program was the introduction of instrumentation for the Renewable Energy Practicum course. This included National Instruments USB-based data acquisition systems (USB-6009) and LabVIEW; solar intensity meters for measuring solar irradiation levels; 
infrared thermometers; Fluke 87 multimeters; and an optical tachometer for measuring the rotational rate of the wind turbine while operating in the wind tunnel. The addition of data acquisition systems enabled students to conduct more comprehensive testing with the ability to collect both time series and time-averaged voltages for each of the experiments.

A final change was the introduction of exams to the Renewable Energy Practicum course. These exams were administered using Personal Response Systems and were based on content from a course textbook that pertained to the experiment (solar photovoltaic, wind energy, solar thermal, or integration / energy storage) that had been conducted the previous week.

One significant observation was made while interviewing students during the final Expo. While asking questions about the paper-based design that the group had created in the Innovation and Entrepreneurship in Renewable Energy course, the students were not able to answer a very fundamental question pertaining to their design. This led the course instructor to suspect that the students had performed a superficial design. Without the need to test a final design, the level of accountability during the design process can be low.

Year 4-2013: The most significant alteration to the 2013 program was to change the requirement in the Innovation and Entrepreneurship in Renewable Energy course from a paperbased design to building and testing a working prototype. This decision was made after the first author visited the SEG electronics market on Huaqiangbei in Shenzhen after the 2012 program concluded. It was noticed that numerous components being sold at the SEG market were the ones being purchased via mail order from a catalog company based in the US for the Renewable Energy Practicum course. By adding a visit to the SEG electronics market after the factory visit in Guangzhou, it became possible to benefit from the strong supply-chain system in China and for the students to source and purchase the components required to build their prototypes. The students were instructed to attempt to negotiate the lowest possible price for their components so as to drive the Manufacturer Suggested Retail Price (MSRP) for their product as low as possible. A second major change was the introduction of 3D printing. A Cubify printer from 3D Systems was purchased and used to print out critical components for each design team.

The above changes resulted in a noticeable increase in the number of student questions throughout the course. It was also observed that teamwork increased significantly, and the intensity associated with a design project was much higher when there was a build requirement.

Year 5 - 2014: The structure of the 2014 program was identical to the 2013 program. The only significant change came when one of the student groups requested access to an Arduino microcontroller for their project. Thus, Arduinos were mail ordered for all of the teams. In the end, half of the teams integrated the single-board computer into their designs. An example of one of these projects is shown in Figure 5. Many of the students had not worked with Arduinos before, but they learned how to utilize them on their own using internet-based information gathering systems with which today's students are extremely comfortable. The only other change was the use of the high-speed rail connecting the Chaoshan region to both Shenzhen and Guangzhou. The 6-hour bus ride was replaced with an approximately 1.5-hour train ride, and proved to be a significantly more comfortable and efficient mode of travel. 


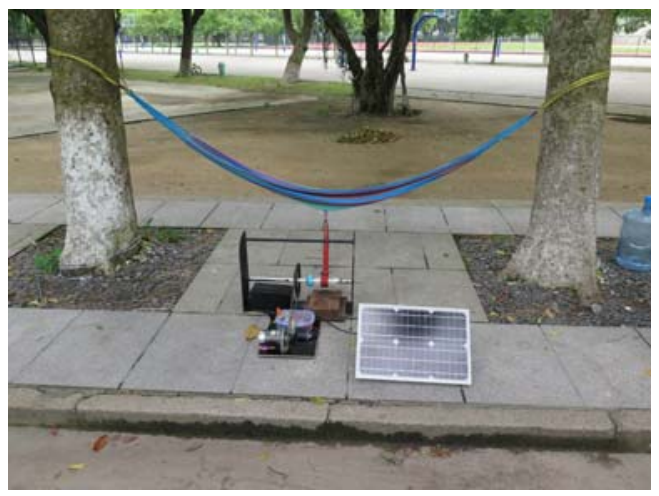

Figure 5: Student Project from 2014 that involved an Arduino (Hammock Rocker)

\section{Learning Outcomes:}

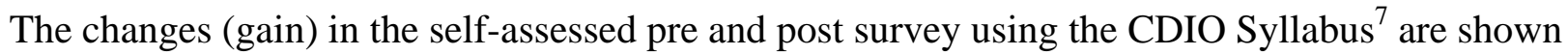
in Figure 6. Values are sorted from bottom to top, starting with the largest post survey value at the bottom. Students report Engineering Entrepreneurship as the area in which they gain the most through the program; this is also the knowledge area that scores the lowest in the pre survey. This is followed by Designing and then Experimentation, Investigation and Knowledge Discovery.

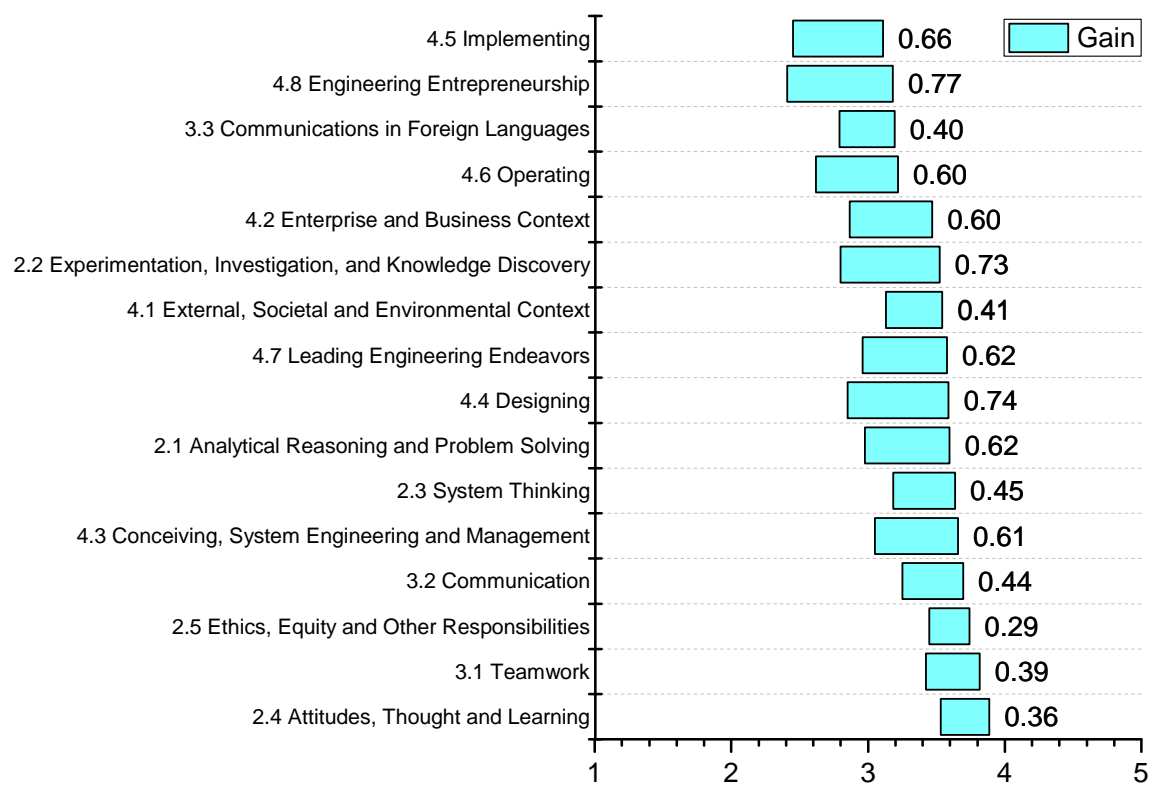

Proficiency Level (1 - have been exposed to; 5 - ability to innovate)

Figure 6: Gain in CDIO Syllabus Proficiency Level (2010-2014; All Students; N=200)

\section{Laboratory Facilities Evolution:}

At the conclusion of each year of the program, the UCalgary instructor meets with personnel from Shantou University and provides recommendations on how the laboratory infrastructure 
could be improved for the following year. This process has enabled a rather significant transformation of the workspace to occur within the five years that the program has been offered. Examples of this evolution can be seen Figure 7.
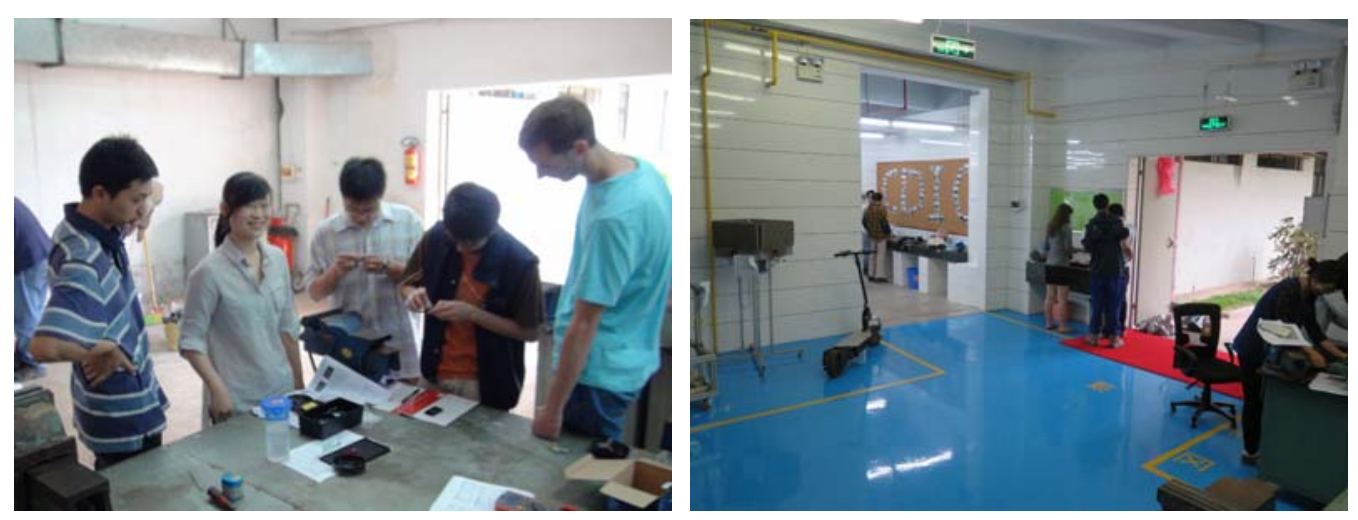

Figure 7: Evolution of Engineering Workspace - Machine Shop Interconnect (left - 2010; right - 2014)

\section{Future Evolution:}

In May 2015, the group study program will be offered for the sixth time. The most significant change to the 2015 program will come through the inclusion of 9 students from the Cheung Kong School of Art and Design (Department of Design) to the Innovation and Entrepreneurship in Renewable Energy course. This will bring the total number of STU students participating in the program to 29. Given the Design students' background, each of the eight design teams should experience an improvement in the aesthetic quality of their final design. A second change is that students from both UCalgary and STU will be surveyed using the Miville-Guzman Universality-Diversity Scale - Short form ${ }^{8,9,10}$ both before and after the program to assess how openness and appreciation of cultural diversity changes through the student experience, and how openness and appreciation have an impact on both the design process and team performance.

A third potential evolution under consideration involves the addition of Technion undergraduate students to the program. Shantou University has partnered with Technion to create the Technion Guangdong Institute of Technology. This is one of two partnerships that Technion has recently engaged in, with the second partnership being with Cornell University and the formation of Cornell Tech in New York City. The addition of Technion undergraduates offers the potential to create teams with a mix of Chinese, Canadian, and Israeli students.

\section{Conclusions:}

This paper has described the evolution of a partnership between the University of Calgary and Shantou University involving a Project-Based Learning course and an Inquiry-Based Learning course. The two courses involved in the partnership are taken by both Canadian and Chinese students, and intercultural understanding is developed through teamwork. Reflective Teaching and Transformative Reflection have been central to the evolution of this program. Using a combination of instructor observations, constant reflection, and student feedback, it has been possible to build a two-course program that achieves in 5 weeks what a typical capstone design 
course will achieve in 8 months. Moreover, the immersion aspect of the courses coupled with the international exposure make this approach to teaching and learning for engineering students a somewhat fascinating and often life-changing experience.

\section{REFERENCES}

1. Powell, S., Ghauri, P., Globalization, DK Publishing, 2008.

2. Downey, G.L., Lucena, J.C., Moskal, B.M., Parkhurst, R., Bigley, T., Hays, C., Jesiek, B.K., Kelly, L. Miller, J., Ruff, S., Lehr, J.L., Nichols-Belo, A., “The Globally Competent Engineer: Working Effectively with People Who Define Problems Differently”, Journal of Engineering Education, Vol. 95, No. 2, 2006, pp 107-122.

3. Hugo, R., Mohamad, A., Gu, P., Sun, H., Bao, N., Lu, X., Shen, M., "Lessons Learned from an International Design-Build Project," Proceedings of the 5th International CDIO Conference, Ecole Polytechnique, Montreal, June 15-18, 2010.

4. Sullivan, J.F., Carlson, L. E. and Carlson, D.W., "Developing Aspiring Engineers into Budding Entrepreneurs: An Invention and Innovation Course," Journal of Engineering Education, Vol. 90, No. 4, pp. 571-576, Oct. 2001.

5. $\quad$ Biggs, J. \& Tang, C. 2011. Teaching for Quality Learning at University, $4^{\text {th }}$ Edition, Open University Press.

6. Hugo, R., Gu, P., "Renewable Energy in the Context of an International Collaboration,” Proceedings of the 6th International CDIO Conference, Singapore Polytechnic, Singapore, June 7-10, 2009.

7. Crawley, E.F., Malmqvist, J., Ostlund, S., Brodeur, D., Edstrom, K., 2014, Rethinking Engineering Education: The CDIO Approach, $2^{\text {nd }}$ Edition, Springer Verlag.

8. $\quad$ Fuertes, J. N., Miville, M. L., Mohr, J. J., Sedlacek, W. E., \& Gretchen, D., “Factor structure and short form of the Miville-Guzman Universality-Diversity Scale,” Measurement and Evaluation in Counseling and Development, 33, pp. 157-169, 2000.

9. Miville, M. L., Gelso, C. J., Pannu, R., Liu, W., Touradji, P., Holloway, P., et al., "Appreciating similarities and valuing differences: The Miville-Guzman UniversalityDiversity Scale,” Journal of Counseling Psychology, 46, 291-307, 1999.

10. Jesiek, B. K., Shen, Y., Haller, Y., “Cross-Cultural Competence: A Comparative Assessment of Engineering Students,” International Journal of Engineering Education, Vol. 28, No. 1, pp. 144-155, 2012. 